\title{
Enquiry into Cultivating Intercultural Nonverbal Communicative Competence in College English Teaching
}

\author{
Zhen Wang \\ Zhejiang Gongshang University, Hangzhou, China \\ Email: ywdave@163.com
}

\begin{abstract}
As a college English teacher, the author has witnessed many teachers who focus on linguistic competence of students or high marks in academic examinations. It is one of the main reasons for low efficiency in college English teaching that nonverbal communication is neglected in daily classroom teaching. This paper deals with the necessity and importance of using nonverbal communication in college English teaching and examines the four categories of nonverbal communication which consist of body language, paralanguage, object language and environmental language. Furthermore, the author aims to figure out several tentative suggestions on how to cultivate students' intercultural nonverbal communication competence in college English teaching.
\end{abstract}

Index Terms - nonverbal communication, competence, college English teaching

\section{INTRODUCTION}

In the past two decades, college English teaching has made great achievement in China. According to College English teaching curriculum requirements published in the year 1985, 1999, 2004 and 2007, the objective of college English teaching is shifting from language competence to the application of language competence, and finally to communication competence. Communication competence consists of two types-verbal communicative competence and nonverbal communicative competence. Nonverbal communication is of great importance with its six functions: accenting, complementing, repeating, substituting, contradicting and regulating. And it usually occurs at the same time as the verbal discourse and creates different effects in different situations. Much attention should be attached to its functions in college English teaching for its high efficiency. This paper deals with the necessity and importance of using nonverbal communication in college English teaching, the categories of nonverbal communication as well as several tentative suggestions on how to cultivate students' intercultural nonverbal communication competence in college English teaching.

\section{NECESSITY AND IMPORTANCE OF USING NVC IN COLLEGE ENGLISH TEACHING}

Samovar, L., et al (1981) positively express their view that most authorities believe that in a normal two-person conversion, the verbal rents carry less than $35 \%$ of the total social meaning of the situation and that more than $65 \%$ is carried on the nonverbal band. That is to say, nonverbal communication plays a vital role as well as the oral counterparts.

Many researchers show that the relationship between teachers and students can be improved if teachers make effective use of nonverbal communication. Besides, students' cognitive ability and efficiency in learning will be promoted (Cooper, 1988).

Thus, in school education, nonverbal communication plays a positive role in cultivating the students' characters. Teachers are usually respected, and factually, what or how the teachers say and do will be possibly imitated by the students (sometimes in a subconscious way). In a word, teachers' graceful nonverbal communication can help to improve the students' artistic-appreciation and moral character.

The affection of it on the students is reflected not only by establishing a good example, but also shortening the teacher-student estrangement, by which a more harmonious studying atmosphere is created. Furthermore, the characteristics of theoretic and abstraction of knowledge also requires the vivid, dramatic and accessible gestures to make it specific and figurative. As a result, the students' interest is motivated and the effect of teaching is greatly improved. In the process of analyzing the performance of the students in the classroom, we find that nonverbal communication (such as the smile or the facial expression, etc.) of the teachers can arouse more reactions and draw more attentions from the students. If they use some appropriate gestures when they deliver the lecture, their class can be more lively and interesting. 
About this issue, an interview has been made among 80 non-English major second-year students in Zhejiang Gongshang University. They were asked to think about the importance of nonverbal communication used by English teachers in daily class. Here is the result (see Table 1):

TABLE 1

THE RESULTS OF QUESTIONNAIRE TO SURVEY THE IMPORTANCE OF NONVERBAL COMMUNICATION IN DAILY ENGLISH CLASS

\begin{tabular}{|l|l|l|}
\hline Number of respondents & Percentage $(\%)$ & Attitude towards the importance of nonverbal communication in daily English class \\
\hline 58 students & 72.5 & Of great importance, helpful for students to learn English a lot \\
\hline 17 students & 21.25 & Of importance, helpful for students to learn English to some extent \\
\hline 3 students & 3.75 & Of little importance, helpless for students to learn English. \\
\hline 2 students & 2.5 & I don't know. \\
\hline
\end{tabular}

This result presents that nonverbal communication plays a significant role in teaching. And in the environment of the class, non-verbal communication can have some special supplementary functions as follows:

(1) Explaining some cultural background information of western countries or about the text, the teacher can use nonverbal communications to present. In this way, he can tell differences between Chinese culture and western culture clearly.

(2) Nonverbal communication can help the teacher to organize the teaching process.

(3) Nonverbal communications can help the teacher control the whole class. Teachers can use them to encourage good performances of the students and also restrain their bad deeds.

(4) Nonverbal communications can benefit the communications between students and teachers

Noticing the importance of using nonverbal communication in college English teaching, college English teachers should improve their own cross-cultural consciousness consistently and attach more attention to develop students' nonverbal communicative competence. What's more, they should introduce nonverbal communication cues into college English teaching with a view to cultivating students' intercultural communicative competence.

\section{Four CATEGORIES OF NONVERBAL COMMUNiCATION}

BI Ji-wan (1999) believes that nonverbal communication can be divided into four classes: (1) body language, including basic posture, gesture, basic manners and movements of any part of the body; (2) paralanguage, including silence, turn-taking and any nonverbal sounds; (3) object language, including complexion, smell, clothing, cosmetics, furniture; (4) environmental language, including time, space, colors, city planning and any human effect on nature.

\section{A. Body Language}

Body language refers to the facial and the movements of the speaker to transmit information. It is the reflective and non-reflective actions of the whole body or part of the body. Its main characteristic is that usually accompanied by oral sounds. The facial expressions, the body pose, the gestures, the movements are in accordance with the oral sounds. They are in harmony and complete the task to express the emotions and ideas of the communicators.

As a communicative form, body language seems to be significant in this research as verbal language. Anyone should use body language while he is speaking so as to have better communicative effects. In English teaching, teachers should use body language well so as to make the class lively and interesting. In the process of teaching, teachers usually use the following body language to show their mood or spirit.

1. Eye contact

As an old saying goes, "Eyes are the window of the soul". We communicate a great deal through our eyes, perhaps more than through any other part of the body. Mencius (1986) claims, "Of all the parts of a man's body, there is none more excellent than the pupil of the eye. The pupil cannot be used to hide a man's "wickedness". A study indicates that the time of eye contact between two participants generally adds up to 30\%-60\% of the time of the whole conversation. If two are on familiar terms, the time can reach $70 \%$.

Eye contact is one of the most important types of nonverbal signals in college English classroom. According to Harrison (1974), besides "looking", eyes can serve (1) to seek feedback or to monitor fellow interact ants; (2) to exercise control over communication channels; and (3) to convey specific relationships-particularly dominance or submission, liking or disliking.

Eye contact is the key point of reflecting the emotional communication between students and teachers. It is the most preferable nonverbal behavior in the classroom. The teachers "take care" of every student via eye contact. In a large classroom, this will shorten the physical distance between the teacher and students. A teacher usually confirms, assures, or encourages the students with eye contact. If the teacher can look at the students and cast his sight to every student equally and appropriately, it implies the concern of the teachers for all the students. And it also indicates that the teacher treats every student equally. The students can see the expectation and encouragement as well as the teacher's confidence from the eye contact, which can arouse the students' enthusiasm in learning and create great motivation and inspiration in them. Harrison (1974) once reported that, "In response to a questionnaire, university students said they thought they would be more comfortable with others who, when speaking, listening and sharing mutual silence, looked at them 50 percent of the time as opposes to 100 percent of the time or not at all." 
The teachers can also get some information from their students' eye contact. If the students are confident enough in the learning process, they maintain eye contact with the teachers, otherwise, they avoid; extrovert students keep more eye contact with teachers than introvert students.

In a word, eye contact makes teaching efficient and pleasant. Teachers' eye contact makes students feel important and keep them involved in the learning process. Eye contact is also the most efficient way for students to tell teachers about their puzzled feelings, willingness, and confidence.

2. Facial expression

Face is the most noted part of our body. Facial expression is a look on a person's face, and facial cues are the first information that we give to or receive from others.

An effective college English teacher usually uses facial expressions to signal to his students how they should react to the material the teacher is discussing: when it is interesting the teacher raises his brows, when it is difficult to concentrate, and at exceptionally difficult points he looks puzzled to signal that he has just asked a difficult question which the students need to think about.

A smiling teacher is thought to convey warmth. Smith (1984) thinks that such a teacher promotes a supportive and non-threatening classroom atmosphere, which aids students' positive attitudes and corresponding achievement. If a teacher smiles frequently, she will be perceived as more likable, friendly, warm and approachable. Smiling is often contagious and students will react favorably and learn more. In fact, most university students expect their teachers to have rich facial expressions and to smile from the beginning to the end in college English class.

There is no doubt that the facial expression of the teachers should be kind and amiable. From their facial expression, we can find out that the good and responsible teachers are full of enthusiasm. They deliver the lectures with full emotions, which can arouse the emotional resonance in the students.

3. Posture

Posture refers to the general way we carry our body, especially the back, shoulders and head while standing, lying, etc. Posture, as the term suggests, can be in static state. The position of the entire body plays an important role in interpreting nonverbal communication.

For a college English teacher, his/her posture can show his state of mind and his teaching enthusiasm. Standing or sitting in a relaxing professional manner is a positive posture, which can arouse students' positive attitude. This kind of posture can show that the teacher is approachable, receptive and friendly. Being comfortably upright, squarely facing the students, and evenly distributing the weight are to move to change students' mood, draw students' attention, or reinforce some ideas.

4. Gesture

Gesture is the nucleus of the body language. In a broad sense, it refers to specific body movements that carry meanings; in a narrow sense, gestures are hand movements that are closely related to speech, illustrating or supplementing it.

The gestures of the teachers have three functions: clarify and describe the facts; emphasize the fact; draw the students' attention. So teachers should combine their oral sound and gestures to make the class lively and dynamic. However, whatever gestures the college English teachers use, they should be sure to have them come naturally from the material they are presenting. If the Chinese teacher imitates foreign gestures in an awkward way, the students will feel disgusted. Most students can not accept the fact that their English teachers who are native Chinese behave exaggeratingly as foreign teachers. In general, they appreciate natural gestures.

Teachers should also observe their students' gestures carefully and then decide what to do next in an English class. If a student frequently scratches his ear, or rubs his eye, or cups his head in his hands, it shows that the student is not interested in the lecture. Conversely, if a student presses his clenched hand close to his cheek, it is a sign of great interest in the lecture.

5. Movement

The psychological research suggests that compared to the static or motionless objects, the moving objects are more observable and can attract more attention from the people. The movement of the teachers should aim at concentrating the students in listening to the lecture, so the movement should be limited to a certain degree. Or else, it will result differently.

\section{B. Paralanguage}

Teachers also use the paralinguistic features to arouse students' interest, inflame the students with a curiosity to learn, and draw their attention. Talking is dominant in classroom teaching; therefore, the teacher's voice has a powerful impact on students. The voice is characterized by paralanguage, which includes intonation, volume, rate, quality, etc.

1. Intonation

Intonation is referred to the change of the pitch when people talk, which often results in some particular mode of the tune. The most familiar intonation is raising tone, falling tone, first rising and then falling tone, or first falling and then rising tone, etc. The unusual use of the intonation often brings some deep meaning. For example, "who are you?" If people use the normal intonation, that is to say, falling tone, then it results in the literal meaning. It means the determination and the confidence of the speaker. It is a question to ask the identity of the listener. However, if people use the first rising and then falling tone, then it means that the speaker is disgusted with the listener. If the speaker uses 
the short falling tone, then it is another way to show looking down upon. If the speaker uses the rising tone, it means to doubt, to surprise, and to ask. Besides, students do not like teachers who speak with a monotonous tone; instead, they like teachers with sonorous voice who talk with emotions and change their voice to cater to the need of the context.

2. Volume

A teacher's voice needs to be loud enough to cover the whole class, such that students can follow teachers' talking. If the teacher raises his voice to some special points, then it means, "Please pay attention. It is very important". Teachers should take control of the volume according to the space of the classroom. If a teacher speaks loudly, both the teacher and the students will feel tired easily. But if his voice is too low or faint, students cannot hear clearly what he is speaking. Consequently, it is very hard to meet the teaching target.

3. Rate

Rate refers to the quantity of the words spoken in every minute. The rate of teachers' voice is not always the same. Generally, a teacher speaks at a normal speed, but sometimes speeds up or slows down for special purposes. In different situations and to different students, teachers should use different rate of talking. Especially in English class, teachers should slower their speed in talking to some elementary or intermediate learners. But to those advanced learners, teachers should speed up and talk in a normal rate.

\section{Object Language}

Object language often refers to the artifacts, which include cosmetics, accessories, adornments, clothes and the furniture. It is a routine for all cultures that one's dress must correspond with his or her social status or occupation. English teachers should pay attention to their appearance and looks. Their appearance should be proper, comfortable and confident. Dressing properly and professionally can make teachers feel confident. Women teachers use a little make up and wear their hair neatly. Some of them wear body adornments like earrings and rings. The clothes they wear should be tidy, clean, dignified and suitable, which can bring people some feeling of beauty and grace. Teachers cannot pursue the resplendent fashion too excessively. Their hairstyle can be the new style, but it should not be exaggerated.

In addition, the odor of the body and the environment should be used appropriately. If these odors are too strong, they will affect the communication between teachers and students. The teaching may result in an ineffective one.

\section{Environmental Language}

Environmental language is an important form of nonverbal communication, which includes time, space, and color, etc.

1. Time

Different cultures have different attitudes toward time. Chinese people belong to the past-orientation of time concept, for instance, children in China like to pretend SUN Wu-kong in their childhood; while the western children like to be Superman or Spiderman since they prefer future-orientation.

In teaching class, teachers are expected to make a good control of time. They are required to be a little earlier to enter the classroom and they must measure time to end the lesson at appropriate time.

2. Space

Based on teaching content, teaching method, and students' participation, the pattern of seating can fall into three types: the traditional arrangement, the horseshoe arrangement, and the modular arrangement (Cooper, 1988) (see Figure $1)$ :

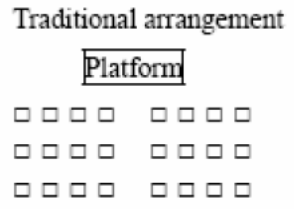

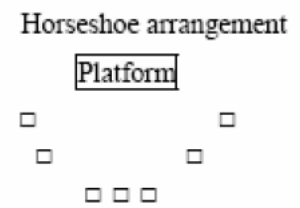

Figure 1 Patterns of seating

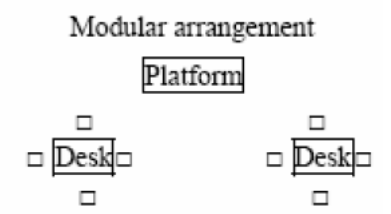

To encourage the students to take part in the activities actively, the seats of the students can be changed according to various demands. In the pattern of traditional arrangement, desks are arranged in a series of straight rows. "This pattern is a major factor in which students will be the ones (those in front and middle rows) to interact most with the teacher. It does not matter whether the seats are assigned or self-directed" (Miller, 1981). Apart from the strong point of interaction between students and teachers, this pattern is easy for teachers to control class because of less communication among students. In addition, this pattern gives the birth to showing teachers' status and dominance. Moreover, Jeremy Harmer (2000) expresses other advantages of this pattern: "It means that the teacher has a clear view of all the students and the students can all see the teacher...It makes lecturing easy; enabling the teacher to maintain eye contact with the people he or she is talking to. It also makes discipline easier since it is more difficult to be disruptive when you are sitting in a row". The second pattern of seating is the horseshoe arrangement. Compared with the traditional one, this pattern is not only helpful for communication between students and teachers but also for communication among students themselves. However, the third pattern is most beneficial for the communication among students. 


\section{Tentative Suggestions on Cultivating Students’’ INVC in College English Teaching}

In the past, college English teaching is always teacher-centered. There is hardly any communication between teacher and students, let alone nonverbal communication. In order to get an effective teaching result, college English teaching should focus on communicative techniques of the verbal as well as nonverbal processes in target language and culture instead of only focusing on the explanation of English vocabulary and grammar. Here are some suggestions as follows:

(1) To introduce nonverbal behaviors in target language and culture.

Teachers must be culturally flexible and versatile. To do this teachers must take as much effort to become aware of the cultural values in the target language and help the students develop linguistic, nonverbal, and cultural skills. The teacher can make the classroom environment culturally versatile by hanging up pictures, posters, or having a classroom exhibit that reflects cultural backgrounds in the target language. This could be an excellent stimulus for discussing cultural similarities and differences among students.

Foreign language teachers should be aware of and impact the unique cultural characteristics which nonverbal behaviors represent foreign language teachers bear an important responsibility to relay these cultural features to their students. Perhaps more attention should be paid to using foreign languages and their nonverbal accompaniments in actual situations.

(2) To develop the awareness of nonverbal intercultural difference.

To be aware of the existence of discrepancy between cultures is the first step to walk into the door of successful intercultural communication. Since the existence of nonverbal cultural difference forms the barrier to intercultural communication, it is understood that teachers order students to observe and spot the difference so that students can avoid the misunderstanding caused by it. For example, if you are going to interact with an Indian, you should know their own culture-oriented behaviors, their manners of refusal, the taboo of eating beef, and the like.

(3) To encourage students to read extensively.

Extensive reading is a widely used technique to develop students' cultural awareness of nonverbal communication. The teacher should encourage students to read materials on the target culture such as authentic newspapers, advertisements, journals, short stories, novels, plays and other types of literary works. Extensive reading of various styles of articles will help students understand more about people in the target culture, and the increase in cultural knowledge will also help learners improve their understanding of various materials. Materials on the target culture may serve as an introduction to the history, arts, literary works, geographical conditions, economy, society, nationality, science, technology, beliefs, value systems, concepts of the world, using of time and space of the target language.

In the process of reading students will not only have an overall understanding of the target culture, but also have a comparison between the native culture and the target culture. They take the opportunity to compare people's different traditions, different beliefs, different norms and different concepts. Through comparison, students will easily have a clear idea about the differences and similarities between the native culture and the target culture and rapidly develop their intercultural awareness.

(4) To use visual aids.

Apart from extensive reading, visual aids can also be used to develop students' intercultural awareness. Usually, visual aids such as films, slides, video and TV programs can give students very interesting and attractive descriptions about people's actions, reactions, expressions, emotions and many other differences. Seeing films, watching slides, watching TV or video in the target culture are the very direct channels for students to observe cultural differences. Because of its vivid manifestation with pictures, sounds, and music, consciously or unconsciously, students will learn more about different customs, values, religions and beliefs in other cultures. If the teacher can make some appropriate comments on those cultural features that are different from the students', the students will gain great benefits. After the viewing students may compare notes and supplements each other's observations and findings.

(5) To introduce some tips on nonverbal communication

In the teaching process, the teacher may use different methods to cultivate students' nonverbal communicative competence. For example, when presenting a text, the teacher may ask students to find some of the expressions involved in nonverbal behaviors and encourage them to imitate these actions in the target language. While the students are practicing a dialogue, the teacher may ask them to perform with combination of verbal and nonverbal behaviors in the activity.

\section{CONCLUSION}

The ignorance of nonverbal communication is one of the main reasons for low efficiency in college English teaching. In modern classrooms where students are learning in teachers' accompaniment, teachers need to understand and apply the approaches and techniques to maintain a good atmosphere in class and enhance teaching with the use of nonverbal communications. As college English teachers, we must make students feel interested in their lessons. The use of nonverbal communication can not only attract the students' attention, but also deepen their impression and imagination.

\section{REFERENCES}

[1] BI J. W. (1999). Intercultural communicative communication. Beijing: Foreign Language Teaching and Research Press. (in 
Chinese)

[2] CHEN Li-fu. (1986). The Confucian way: A new and systematic study of "The four books". London: Taylor and Francis. (in Chinese)

[3] Cooper, P. J. (1988). Speech communication for the classroom teacher. Scottsdale: Gorsuch Scarisbbrick.

[4] Harrison, R. R. (1974). Beyond words. N. J.: Prentice Hall, Inc.

[5] Jeremy, H. (2000). How to teach English: Foreign language teaching and research. New York: Teachers College Press.

[6] Miller, P. W. (1981). Nonverbal communication. Washington, D. C: National Education Association.

[7] Samovar, L. \& Porter, R. (1981). Understanding intercultural communication. Belmont Calif: Wadsworth Pushing Company.

[8] Smith, Howard A. (1984). Non-verbal behavior aspects of teaching in nonverbal behavior. Lewiston, NY: C. J. Hogrefe.

Zhen Wang was born in Yiwu, China in 1982. He received his Master degree in applied linguistics from Harbin Institute of Technology, China in 2005.

He is currently a lecturer in the School of Foreign Languages, Zhejiang Gongshang University, Hangzhou, China. His research interests include intercultural communications and American literature. 